Research Article

\title{
Assessment of Finger Proprioception and Lateral Pinch Strength in Amateur and Professional Guitarists
}

\author{
Pranita Ganjave', Hannah D'souza ${ }^{2}$
}

${ }^{1}$ Assistant Professor, ${ }^{2}$ BPT Intern, DY Patil Deemed to be University, School of Physiotherapy, Nerul, Navi Mumbai, India. DOI: https://doi.org/10.24321/2349.2880.201916

\section{I $\quad \mathbf{N} \quad \mathbf{F} \quad \mathbf{O}$}

\section{Corresponding Author:}

Hannah D'souza, DY Patil Deemed to be University, School of Physiotherapy, Nerul, Navi Mumbai, India.

E-mail Id:

hannahdsouza98@gmail.com

Orcid Id:

https://orcid.org/0000-0002-6764-2118

How to cite this article:

Ganjave P, D'souza H. Assessment of Finger Proprioception and Lateral Pinch Strength in Amateur and Professional Guitarists. Ind J Youth Adol Health 2019; 6(4): 6-11.

Date of Submission: 2020-05-08

Date of Acceptance: 2020-05-26

\section{$\begin{array}{llllllll}\text { A } & \text { B } & \mathbf{S} & \mathbf{T} & \mathbf{R} & \mathbf{A} & \mathbf{C} & \mathbf{T}\end{array}$}

Background: Guitarists use complex and different movement patterns in both hands simultaneously. Applying pressure on the strings and strumming both require good strength whereas playing the melody on the fret-board demands good proprioception. There is a need to find out if guitarists perform functionally well with respect to pinch strength and proprioception which are prerequisites for playing the guitar. Therefore, the aim of the study is to assess and compare finger proprioception and pinch strength in amateur and professional guitarists.

Methodology: A cross sectional study was conducted on 50 amateur and 50 professional guitarists from Mumbai. A self-made questionnaire including their demographic data was asked to be filled. Proprioception was measured using the pinch aperture proprioception device and lateral pinch strength was measured using the Jamar ${ }^{\circledast}$ Hydraulic Pinch Gauge. The average of 3 trials was taken for finger proprioception and lateral pinch strength. The data obtained was then taken for further analysis.

Result: Professional guitarists had better finger proprioception ( $p$ value $=0.0001$ for both right \& left hands) and lateral pinch strength ( $p$ value $=0.0159,0.0001$ for the right \& left hand respectively) than amateur guitarists. Also, the left hand had better finger proprioception ( $p$ value $<0.0001,0.0059$ for amateur \& professional guitarists respectively) and right hand had better lateral pinch strength ( $p$ value $=0.0001$ for both professional and amateur guitarists) in both professional and amateur guitarists.

Conclusion: Professional guitarists had significantly better finger Proprioception and lateral pinch strength as compared to the amateur guitarists.

Keywords: Musicians, Finger Proprioception, Pinch Strength, Guitarists

\section{Introduction}

In this day and age, more people want to learn to play an instrument as compared to before. This may be due to various reasons such as reducing stress, recreational 
purposes, career, etc. Musicians are categorised in amateurs and professionals depending on their skill and reason for instrument playing. Music is a source of employment for a professional musician, while, an amateur musician does music in the free time whether paid or unpaid. ${ }^{1}$

Playing a musical instrument requires the integration of multimodal sensory and motor information. ${ }^{2}$ Each category of instruments has its own physical demands. Playing any instrument demands repetitive and precise movements in extended durations of non-ergonomic posture such as while playing the guitar which belong to the strings family. Guitar playing appears effortless; however, there are a great deal of physical demands associated with it. The right hand does the strumming and/ or picking of the strings, and fingers of the left hand are used for fretting the strings, i.e., controlling the acoustic range of the instrument by varying effective string length. ${ }^{3,4}$ The energy put into the string by the guitarist's finger accounts for the sound produced. ${ }^{5}$

Musicians need a meticulous control of movement while playing their instrument, which demands good proprioception. "Proprioception is the awareness of position and movement of the body and its segments without visual cues." ${ }^{6}$ The skin, joints, ligaments, tendons, and muscle contain mechanoreceptors or proprioceptors which derive proprioceptive feedback signals. ${ }^{7}$ String players press the string in a highly precise manner so that the right pitches are achieved consistently ${ }^{8}$ for which pinch strength and proprioception are of utmost importance. Developing proper motor programs between the brain and the hands so as to execute different patterns and techniques with paramount efficiency is vital for a guitarist or any musician. ${ }^{9}$ Playing different sequences in both hands simultaneously for a guitarist requires precise functional coordination of both hands. ${ }^{10}$

Due to the above-mentioned reasons there is a need to find out if guitarists perform functionally well with respect to pinch strength and proprioception which are both prerequisites for playing the guitar. Since there is a paucity of literature with respect to pinch and proprioception in guitarists, therefore, the aim of the study is to assess and compare finger proprioception and pinch strength in amateur and professional guitarists.

\section{Methodology}

A cross sectional study was conducted in a 6 month period from August 2019 to January 2020 on 50 amateur and 50 professional guitarists recruited from music schools, academies and bands in Mumbai. The subjects were aged between 18 to 35 years were right hand dominant and had no past history of any musculoskeletal or neurological problem. The nature and purpose of study was explained and prior consent was obtained from the participants. A self-made questionnaire (see Annexure) including their demographic data was asked to be filled. The proprioception was measured using the Pinch aperture proprioception device $^{7}$ and lateral pinch strength was measured using the Jamar ${ }^{\circledR}$ Hydraulic Pinch Gauge (Sammons Preston, Inc.). ${ }^{11}$

\section{Statistical Analysis}

Means \pm Standard Deviations (SD) were used to describe variables. Normality of the data was verified using the Kolmogorov-Smirnov test. Paired t-test and unpaired t-test was used for within group analysis and between group analysis respectively. Significance level was set at $<0.05$. Confidence interval was set at $95 \%$.

\section{Procedure}

Institutional ethics committee approval was taken prior to the beginning of the study. The subjects falling into the inclusion and exclusion criteria were taken for the study. A consent form stating the purpose of the study was taken. The self-made questionnaire including their demographic data was asked to be filled by the study samples. The procedure was then explained to them.

\section{Finger Proprioception}

Finger proprioception was measured using the pinch aperture proprioception device. ${ }^{14}$ This included a goniometer with its fulcrum fixed on a cardboard box (Figure 1a). The goniometer arms included circular pads for the placement of the tips of the thumb and first finger. The subject was asked to rest their hand on the table and to hold the perpendicular pads, using their index finger and thumb. Subjects were familiarized with the device and then performed two practice trials during which the index finger and thumb were moved passively by the examiner from the starting position of $30^{\circ}$ to the target position of $15^{\circ}$ with their eyes closed. In these practice trials, the subjects had to memorize that position. During the testing, the examiner moved the goniometer arms to the starting position $\left(30^{\circ}\right)$ and instructed the participant to pinch their fingers actively trying to reproduce the target position $\left(15^{\circ}\right)$ without visual feedback. The average of 3 trails was collected for further analysis. ${ }^{12}$

\section{Later Pinch Strength}

The lateral pinch strength was measured using the Jamar Hydraulic Pinch meter ${ }^{13}$ (Figure $1 b$ ). The subject had to be seated upright. The testing arm was placed on a table with elbow flexed at $90^{\circ}$, wrist in neutral. The pinch gauge was placed between the flexed PIP joint of the index finger and thumb. The subject was asked to squeeze, hold and then release. Average of 3 trails was collected for further analysis. $^{13}$ 


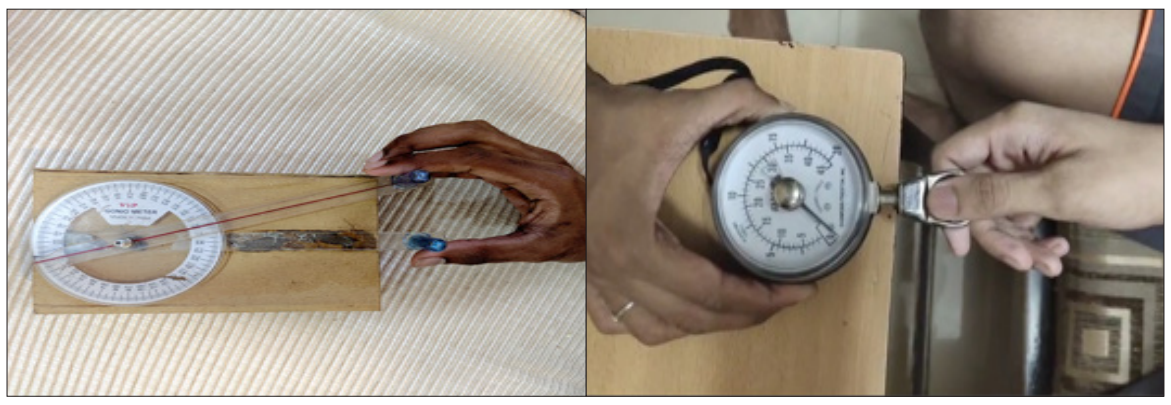

Figure I(a): Measurement of finger Figure I(b): Measurement of lateral proprioception using the Pinch aperture proprioception device pinch strength using the $\operatorname{Jamar}^{\circledR}$ Hydraulic Pinch Gauge

Figure I.Outcome measures - (a)Pinch aperture proprioception device and (b) Jamar ${ }^{\circledR}$ Hydraulic Pinch Gauge

\section{Result}

100 guitarists from Mumbai were assessed for finger proprioception and lateral pinch strength. Table 1, represents the demographic characteristics of the professional and amateur guitarists. The guitarists playing styles were confined to rhythm, lead and bass. Amateur guitarists played only for recreational purposes. There were 35 students and 14 self-trained amateur guitarists. The professional guitarists played for a living. There were 6 guitar tutors, 36 band members and 8 choir members.

Table I.Demographic Data of amateur and professional guitarists

\begin{tabular}{|c|c|c|}
\hline & $\begin{array}{c}\text { Amateur } \\
\text { Guitarists }\end{array}$ & $\begin{array}{c}\text { Professional } \\
\text { Guitarists }\end{array}$ \\
\hline No. of Subjects & 50 & 50 \\
\hline Age (mean \pm SD) & $21.92 \pm 3.78$ & $23.2 \pm 4.69$ \\
\hline $\begin{array}{c}\text { Years of playing } \\
\text { (mean } \pm \text { SD) }\end{array}$ & $1.6 \pm 1.16$ & $7.98 \pm 3.44$ \\
\hline $\begin{array}{c}\text { Age of Commencement of } \\
\text { playing (mean } \pm \text { SD) }\end{array}$ & $19.78 \pm 4.13$ & $14.98 \pm 4.44$ \\
\hline $\begin{array}{c}\text { Hours of playing perweek } \\
\text { (mean } \pm S D \text { ) }\end{array}$ & $2.42 \pm 1.45$ & $7 \pm 3.11$ \\
\hline Gender & Male: 35 & Male: 47 \\
Female: 15 & Female: 3 \\
\hline
\end{tabular}

Paired t test was used for comparison between professional and amateur guitarist's finger proprioception and lateral pinch strength in left and right hand. Between group analysis showed that professional guitarists had better finger proprioception ( $p=0.0001$ for both right \& left hands) and lateral pinch strength $(p=0.0159,0.0001$ for the right \& left hand respectively) than amateur guitarists (Table 2). Unpaired t test was used for comparison of right and left hand finger proprioception and lateral pinch strength in professional and amateur guitarists. Within group analysis shows that, the left hand had better finger proprioception ( $p=0.0001,0.0059$ for amateur \& professional guitarists respectively) and right hand had better lateral pinch strength ( $p=0.0001$ for both professional and amateur guitarists) in both professional and amateur guitarists (Table 3 ).

Table 2.Comparison between professional and amateur guitarist's (MEAN \pm SD) finger proprioception and lateral pinch strength in left and right hand (between group analysis)

\begin{tabular}{|c|c|c|c|c|}
\hline & & $\begin{array}{l}\text { Amateur } \\
\text { Guitarist }\end{array}$ & $\begin{array}{c}\text { Professional } \\
\text { Guitarist }\end{array}$ & p-value \\
\hline \multirow{2}{*}{$\begin{array}{l}\text { Finger } \\
\text { Proprio- } \\
\text { ception } \\
\text { (degrees) }\end{array}$} & $\begin{array}{l}\text { Right } \\
\text { Hand }\end{array}$ & $\begin{array}{c}19.65 \pm \\
1.623\end{array}$ & $17.13 \pm 2.784$ & $<0.0001$ \\
\hline & $\begin{array}{l}\text { Left } \\
\text { Hand }\end{array}$ & $\begin{array}{c}17.99 \pm \\
2.033\end{array}$ & $16.14 \pm 1.311$ & $<0.0001$ \\
\hline \multirow{2}{*}{$\begin{array}{l}\text { Lateral } \\
\text { Pinch } \\
\text { strength } \\
\text { (kilogram } \\
\text { force) }\end{array}$} & $\begin{array}{l}\text { Right } \\
\text { Hand }\end{array}$ & $\begin{array}{c}14.38 \pm \\
3.126\end{array}$ & $15.69 \pm 2.082$ & 0.0159 \\
\hline & $\begin{array}{l}\text { Left } \\
\text { Hand }\end{array}$ & $\begin{array}{c}11.54 \pm \\
2.443\end{array}$ & $13.91 \pm 2.123$ & $<0.0001$ \\
\hline
\end{tabular}

Table 3.Comparison of right and left hand finger proprioception and lateral pinch strength (Mean \pm SD) in professional and amateur guitarists (within group analysis)

\begin{tabular}{|c|c|c|c|c|}
\hline & & $\begin{array}{l}\text { Right } \\
\text { hand }\end{array}$ & $\begin{array}{l}\text { Left } \\
\text { hand }\end{array}$ & p-value \\
\hline \multirow{2}{*}{$\begin{array}{c}\text { Finger } \\
\text { Proprio- } \\
\text { ception } \\
\text { (degrees) }\end{array}$} & $\begin{array}{l}\text { Amateur } \\
\text { Guitarist }\end{array}$ & $\begin{array}{c}19.65 \pm \\
1.623\end{array}$ & $\begin{array}{c}17.99 \pm \\
2.033\end{array}$ & $<0.0001$ \\
\hline & $\begin{array}{c}\text { Professional } \\
\text { Guitarist }\end{array}$ & $\begin{array}{c}17.13 \pm \\
2.784 \\
\end{array}$ & $\begin{array}{c}16.14 \pm \\
1.311 \\
\end{array}$ & 0.0059 \\
\hline \multirow{2}{*}{$\begin{array}{l}\text { Lateral } \\
\text { Pinch } \\
\text { strength } \\
\text { (kilogram } \\
\text { force) }\end{array}$} & $\begin{array}{l}\text { Amateur } \\
\text { Guitarist }\end{array}$ & $\begin{array}{c}14.38 \pm \\
3.126\end{array}$ & $\begin{array}{c}11.54 \pm \\
2.443\end{array}$ & $<0.0001$ \\
\hline & $\begin{array}{c}\text { Professional } \\
\text { Guitarist }\end{array}$ & $\begin{array}{c}15.69 \pm \\
2.082\end{array}$ & $\begin{array}{c}13.91 \pm \\
2.123\end{array}$ & $<0.0001$ \\
\hline
\end{tabular}




\section{Discussion}

The aim of the study was to assess finger proprioception and lateral pinch strength in amateur and professional guitarists.

The first objective was to compare the finger proprioception between amateur and professional guitarists (Table 2). According to the result obtained, the professional guitarists had better finger proprioception than the amateur guitarists with respect to both right and left hands. In a study, they found out that in professional musicians, the pattern of sensorimotor organization is organized less differentially than in non-musicians. Motor control of adjacent fingers may be facilitated due to this pattern, (e.g. for the playing of fast passages) which may prove as an advantage. ${ }^{14}$ Increased finger proprioception might also account for the years of training and difference in weekly practice intensity between the amateurs and professionals. A similar study suggested that there could be enhancement or preservation of domain-general, cognitive control abilities in older adults owing to sustained music-making ability and expertise. ${ }^{15} \mathrm{~A}$ study comparing gray matter volume in professional and amateur musicians found that there was an increased gray matter volume in professional musicians in peri-rolandic, premoter region, superior parietal region and inferior temporal gyrus bilaterally which which are associated with bimanual finger movements, motor learning and skill acquisition. ${ }^{2}$ All of these are significant for a musician.

When the finger proprioception is compared between right and left hands of both amateur and professional guitarists, the left hand seems to have greater finger proprioceptive ability (Table 3). In guitarists, the left hand is the so-called hand of technique. The fingers have to aim at the correct note on the fret-board where there are a hundred possible target ${ }^{16}$ which demands a good proprioceptive input. This could account for the years of training or the age at which the guitarists commenced playing the guitar. The result of the present study are in accordance with study done by author Hortobágyi T et al. that the amount of cortical representation of the digits of the left hand of string players on magnetic resonance was larger than in controls which correlated with the age at which the person had begun to play. ${ }^{17}$ Also, it has been observed that, the left hand skills of right-handed musicians outperformed that of right hand non musicians. They showed a reduced degree of righthand superiority which was mainly due to a left-hand gain and not to a right-hand loss of skill. ${ }^{18}$ The left hand melody helps consolidate control of the fingers involved which in turn involves mental anticipation of each movement that presets muscles to aim the finger most accurately. ${ }^{16}$

Another objective was to compare the lateral pinch strength between amateur and professional guitarists (Table 2). Playing the guitar demands intense practice and playing a repertoire of movement. Each finger is placed and fitted to press the strings at the accurate angle and strength. ${ }^{19}$ According to the results obtained, similar to proprioception, the professional guitarists had better lateral pinch strength as compared to amateur guitarists. It has been observed that the finger skill in guitarist is involved with the exchange of paired fingers in a cross-board movement which increases the strength and separation of the fingers. ${ }^{16}$ Also, practice sessions for guitarists include hours of repetitive movements such as the strumming action. Professional guitarists in the sample had far more practice or playing time per week as compared to amateur guitarists which would include a repertoire of strumming patterns. The amount of practice required to obtain the desired music is done by optimal loading of the muscles to play the rhythm precisely Muscles adapt and grow and muscle fibres increase in strength when they are pushed just beyond their optimal load, first as the nerve networks that supply the muscles become increasingly efficient. ${ }^{17}$

As far as the differences between the right and left hand are concerned with respect to lateral pinch strength, the amateurs and professionals both had better lateral pinch strength in the right hand i.e. the dominant hand or the strumming hand (Table 3 ). The act of strumming requires lateral pinch to hold the plectrum in place or to simply strum the strings with the fingers. This strumming action is done continuously by the right hand. The strumming action is also fast paced. A study using surface electromyography (EMG) on the right hand of professional guitarists concluded that a high degree of stability and consistency in terms of muscular activation, was demonstrated with excellent motor control in them. ${ }^{19}$

Therefore, the results of the present study state that, professional guitarists had significantly better finger proprioception and lateral pinch strength than amateur guitarists. Also, with respect to the upper extremities, left hand had better finger proprioception and right hand had superior values for lateral pinch strength in both professional and amateur guitarists.

\section{Conclusion}

Finger Proprioception and lateral pinch strength was better in professional guitarists as compared to the amateur guitarists. Exercise protocol focusing on finger proprioception and all pinch strength should be incorporated as daily routine exercises to meet the demand of the game and to prevent further injuries to hand.

\section{Acknowledgement}

I take this opportunity to express my sincere gratitude to those people without whose support and concern this project would not have been a success. I am extremely thankful to my guide, Dr. Pranita Ganjave at School of 
Physiotherapy, for all the help, guidance and support throughout the study. Most importantly, I am obliged to the study subjects from Trinity College London Music, Francis Music Academy, Triveni Kala Academy and all the other musicians for their time and co-operation.

\section{Ethical Clearance}

Clearance was obtained from the Institutional ethical committee of D.Y. Patil Deemed to be University, School of Physiotherapy, Navi Mumbai.

Source of Funding: It was a self-financed study

\section{Conflict of Interest: None}

\section{References}

1. Linnett, RJ. Notes of discord: The relationship between multidimensional perfectionism and burnout in amateur and professional musicians. Unpublished undergraduate thesis). University of Northampton, UK. 2016.

2. Gaser C, Schlaug G. Gray matter differences between musicians and nonmusicians. Annals of the New York Academy of Sciences 2003; 999(1): 514-517.

3. Larsen JV, Overholt D, Moeslund TB. The Actuated Guitar: A platform enabling alternative interaction methods. In SMC Proceedings of the Sound and Music Computing Conference. 235-238. Stockholm, Sweden.: Logos Verlag Berlin. 2013.

4. Gast TA. Guitar. U.S. Patent $1,764,679$, issued June 17, 1930.

5. Bartolome, Jan Emanuele. Effects of Wood Attributes on Acoustic Guitar Sound Quality. 2016.

6. Lephart SM, Pincivero DM, Giraido JL, Freddie H Fu. The role of proprioception in the management and rehabilitation of athletic injuries. The American journal of sports medicine 1997; 25(1): 130-137.

7. Abdalghani Y, von Behren T, Levine S, dos Santos M. Pinch aperture proprioception: reliability and feasibility study. Journal of physical therapy science 2018; 30(5): 734-740.

8. Lee Han-Sung, Park HY, Yoon JO, Kim JS, Chun JM, Aminata IW et al. Musicians' medicine: musculoskeletal problems in string players. Clinics in orthopedic surgery 2013; 5(3): 155-160.

9. Solomon JW. What Every Guitarist Should Know: A Guide to the Prevention and Rehabilitation of Focal Hand Dystonia. Guitar Review 133: 1-9.

10. Van Hook C. The Relationship Between Instrumental Music Training and Corpus Callosum Growth. PhD diss., Boston College. College of Arts and Sciences, 2004.

11. Lindstrom-Hazel D, Kratt A, Bix L. Interrater reliability of students using hand and pinch dynamometers. American Journal of occupational therapy 2009; 63(2): 193-197.

12. Yahya A, Kluding P, Pasnoor M, Wick J, Liu W, Santos Md.
The impact of diabetic peripheral neuropathy on pinch proprioception. Experimental brain research 2019; 237(12): 3165-3174.

13. Mathiowetz V, Kashman N, Volland G, Weber K, Dowe M, Rogers S. Grip and pinch strength: normative data for adults. Arch Phys Med Rehabil 1985; 66(2): 69-74.

14. Rosenkranz K, Butler K, Williamon A, Rothwell JC. Regaining motor control in musician's dystonia by restoring sensorimotor organization. Journal of Neuroscience 2009; 29(46): 14627-14636.

15. ElKoura G, Singh K. Handrix: animating the human hand. In Proceedings of the 2003 ACM SIGGRAPH/ Eurographics symposium on Computer animation 2003; 110-119. Eurographics Association.

16. Duncan C. The art of classical guitar playing. Alfred Music, 1995.

17. Hortobágyi T, Maffiuletti NA. Neural adaptations to electrical stimulation strength training. European journal of applied physiology 2011; 111(10): 2439-2449.

18. Bejjani FJ, Kaye GM, Benham M. Musculoskeletal and neuromuscular conditions of instrumental musicians. Archives of physical medicine and rehabilitation 1996; 77(4): 406-413.

19. de Monge, Fernández ND, Vera JG. Study of two stroke techniques with transverse movement of the right hand on classical guitar using surface emg. Arts BioMechanics 2013; 2(1): 19. 


\section{Annexures}

\section{Questionnaire}

1. Full Name

2. Age

3. Mobile no.

4. Email Address

5. Type of Guitar

- Rhythm

- Lead

- Bass

6. Playing Level

- Band

- Orchestra

- Choir

- Tutor

- Student

- Self-Trained

7. No. of years of playing

8. Age of commencement of playing

9. Hours of playing per week

10. Any known neurological condition? (If yes please mention)

- Yes

- No

11. Any known musculoskeletal condition? (If yes please mention)

- Yes

- No

12. Any past injury to the upper limbs? (If yes please mention)

- Yes

- No

13. Hand Dominance

- $\quad$ Right

- Left 